\title{
Perancangan dan Realisasi Grup SMS dengan Sistem Tertanam
}

\author{
Darmawan Utomo \\ Program Studi Sistem Komputer, \\ Fakultas Teknik Elektronika dan Komputer, \\ Universitas Kristen Satya Wacana, Salatiga \\ darmawan@staff.uksw.edu
}

\begin{abstract}
Ringkasan
SMS merupakan media pengiriman pesan teks yang telah ada sejak telepon seluler generasi awal hingga sekarang. Selain itu, setiap operator telekomunikasi masih menyediakan layanan ini. Untuk melayani grup pengguna sms, operator hanya melayani sesama operator. Untuk itu, telah dirancang dan dibuat sebuah sistem yang berperilaku seperti SMS untuk grup tak tergantung operator. Grup SMS ini memiliki dua fasilitas pengiriman, yaitu berdasarkan moderator dan tidak. Fasilitas pendaftaran anggota baik melalui perangkat maupun via SMS. Selain itu juga fasilitas pengiriman USSD, dan Kirim/Terima SMS melalui perangkat maupun SMS.
\end{abstract}

Kata kunci: SMS, grup SMS, USSD, sistem tertanam, SMS gateway

\section{Pendahuluan}

SMS selain sebagai pesan, ketika dihubungkan dengan sistem tertanam dapat digunakan dalam aplikasi seperti mengaktifkan lampu, mematikan alarm mobil, dan pesan berjalan. Pada sistem ini rata-rata bekerja dengan memastikan no seluler pengirim, menerjemahkan perintah, mengaktifkan/mematikan saklar, atau menampilkan pesan. Ada yang dibuat dengan memberikan umpan balik setelah melaksanakan perintah dan ada yang tidak. Kelemahan dari sistem ini adalah pesan seringkali tidak dapat dipastikan sampai tepat waktu karena tergantung dari layanan operator.

Operator juga memiliki layanan-layanan yang menjual fitur SMS seperti grup SMS, Premium SMS, bulk SMS, dan SMS komunitas. SMS memiliki fitur-fitur unggulan seperti tanpa aplikasi tambahan, langsung ke nomor tujuan, dan dapat digunakan pada segala macam perangkat seluler, menjadi bahan promosi operator untuk meningkatkan pendapatan. Kelemahan bulk SMS, grup SMS dan SMS komunitas yang diselenggarakan oleh operator adalah harus dari operator yang sama. Ini akan membatasi anggota dari operator lain. Layanan ini dapat diselenggarakan oleh pihak non-operator dengan cara menyediakan modem dan komputer dengan membuat SMS-gateway. Penggunaan komputer kurang cocok jika hanya ada sedikit anggota, membutuhkan tanggapan secara otomatis, tempat penyimpanan yang kecil, dan rendah-pemeliharaaan, seperti pada lingkungan RT atau perusahaan kecil.

Untuk itu diusulkan sebuah rancangan yang dapat mengatasi masalah pada grup SMS atau SMS komunitas agar dapat menerima/mengirimkan pesan dari/kepada semua operator. Fasilitas yang diharapkan adalah adanya administrator dan mode dengan atau 
tanpa moderator. Administrator diperlukan untuk menambahan dan mengurangi anggota. Mode dengan moderator diperlukan agar sebelum SMS dikirim telah diverifikasi oleh Administrator. Sedangkan mode tanpa moderator akan membuat setiap SMS segera dikirimkan ke semua anggota.

Pada grup SMS dari layanan operator,perubahan data hanya dimungkinkan melalui pengiriman SMS atau melalui fasilitas USSD operator. Oleh karena grup SMS ini dibuat sendiri, perubahan data anggota dapat dilakukan langsung ke perangkat maupun melalui SMS Administrator.

\section{Perancangan}

Perancangan sistem ini dibagi menjadi perangkat keras dan lunak. Perangkat keras memperlihatkan desain sistem tertanam dan koneksinya dengan modem. Sedangkan perangkat lunak ditunjukkan pada gaftar alir sistem yang telah direalisasikan.

\subsection{Perangkat Keras}

Gambar 1 menunjukkan skema perangkat dengan basis sistem mikrokontroler Atmega324 [1] yang terhubung dengan LCD 16x2, keyboard PS2, dan RS232. RS232 port komunikasi pertama dihubungkan dengan modem Wavecom. Pada modem sudah harus disiapkan kartu SIM yang sudah terdaftar di salah satu operator. Deskripsi pin yang dihubungkan dengan perangkat LCD, PS2, dan modem Wavecom ditunjukkan pada Tabel 1.

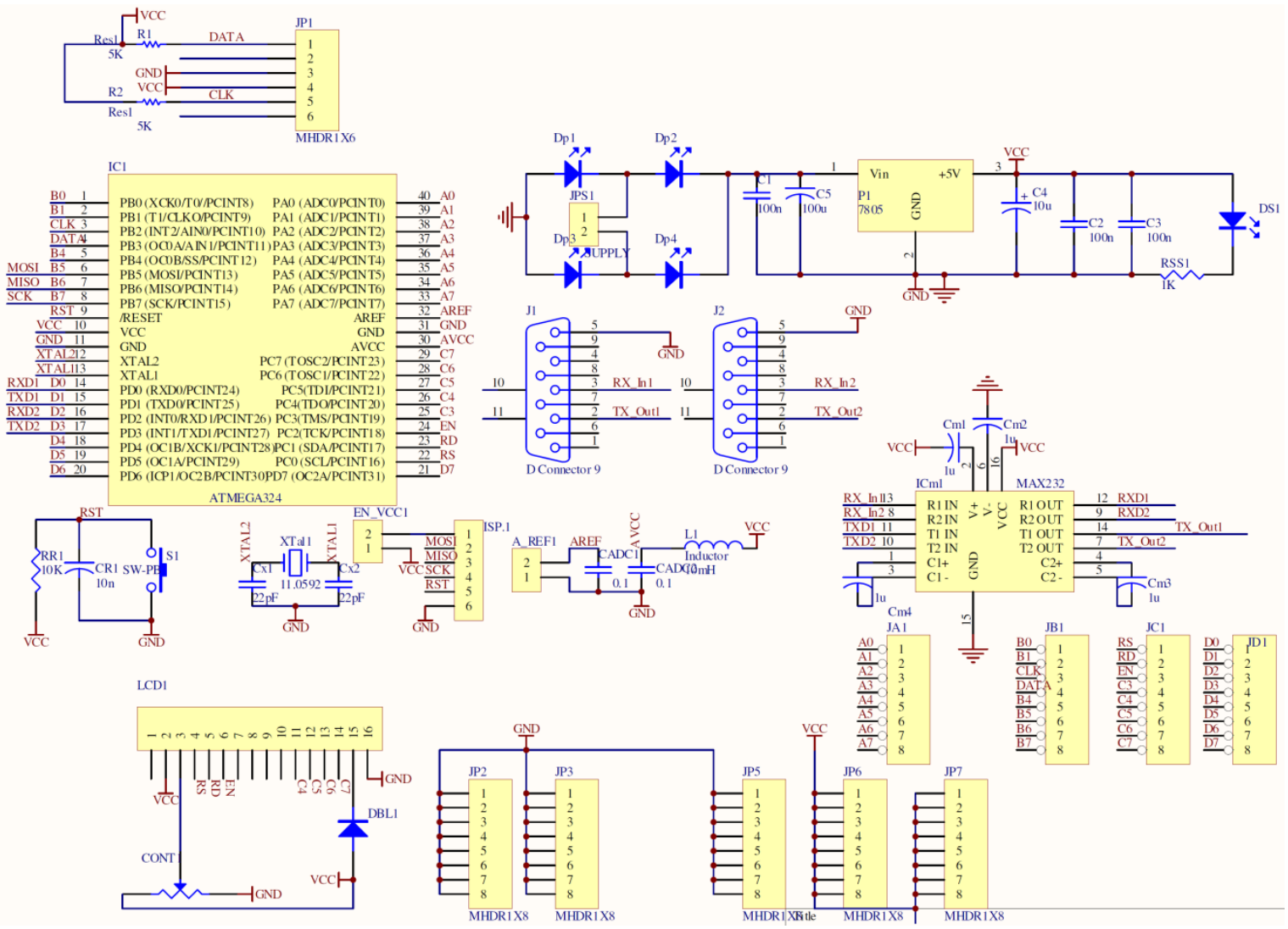

Gambar 1. Skema sistem mikrokontroler dengan antarmukanya. 
Tabel 1. Pin mikrokontroler dan deskripsi pemanfaatannya

\begin{tabular}{|c|c|c|}
\hline No & Antarmuka & Port Atmega324 \\
\hline 1 & LCD 16x2 & PC0-7 \\
\hline 2 & PS2 & PB2 dan PB3 \\
\hline 3 & RS232-com0 & PD0 dan PD1 \\
\hline
\end{tabular}

Dari gambar skema, keluaran dari J1 (DB9) nantinya akan dihubungkan dengan modem Wavecom. JP1 terhubung dengan keyboard PS2. Sedangkan LCD1 merupakan port yang kompatibel dengan pin-pin LCD 16×2.

\subsection{Perangkat Lunak}

Perancangan perangkat lunak diperlihatkan pada Gambar 2.a yang menampilkan menu-menu yang berkaitan dengan akses ke perangkat. Sedangkan Gambar 2.b menampilkan aliran SMS dan perlakuannya yang dipisahkan terhadap pengirim (anggota, admin, non anggota), dan mode yang digunakan apakah dengan atau tanpa moderator.

Perintah-perintah dasar mengakses modem dan kartu sim dapat dilakukan melalui perintah AT. Koleksi perintah AT pada modem Wavecom[2] dipisahkan dalam kelompok seperti perintah umum modem, kontrol panggilan, layanan jaringan, keamanan, phonebook, dan SMS. Beberapa perintah penting yang digunakan pada perancangan perangkat lunak ini ditunjukkan pada Tabel 2.

Tabel 2.Sebagian Perintah AT dan Deskripsinya

\begin{tabular}{|c|c|c|}
\hline No & Perintah AT+ & Deskripsi \\
\hline 1 & CMGR & Membaca SMS \\
\hline 2 & CMGD & Menghapus SMS \\
\hline 3 & CMGL & Melihat SMS berdasarkan tempat penyimpanan \\
\hline 4 & CMGS & Mengirim SMS \\
\hline 5 & CPBR & Mencari nomor seluler berdasarkan nama \\
\hline 6 & CPBF & Menulis nama dan nomor ke phonebook \\
\hline 7 & CPBW & Mencari nama berdasarkan nomor seluler \\
\hline 8 & CPBP & Mengirim perintah USSD \\
\hline 9 & CUSD & Memutus modem dengan jaringan operator \\
\hline 10 & CFUN &
\end{tabular}

Perintah nomor 1-4 adalah perintah yang mengatur akses SMS. Setelah sebuah SMS datang, SMS ini harus dihapus untuk menyiapkan SMS datang berikutnya. SMS datang yang dapat ditampung sejumlah ruang yang disediakan oleh kartu sim operator. Perintah nomor 5-8 berkaitan dengan penambahan, penghapusan, dan pencarian nama dan nomor seluler. Pencarian nomor seluler berdasarkan nama anggota dengan menggunakan perintah $\mathrm{AT}+\mathrm{CPBF}$, dan $\mathrm{AT}+\mathrm{CPBP}$ untuk sebaliknya. Perintah nomor 9 adalah salah satu cara mengirimkan perintah singkat dari modem atau perangkat seluler ke jaringan GSM yang berorientasi sesi, jadi tidak disimpan. Biasanya USSD digunakan untuk mengetahui pulsa yang masih tersedia atau meregistrasi paket layanan operator. Perintah CFUN digunakan untuk menyambung/memutus koneksi antara modem dengan jaringan operator. 


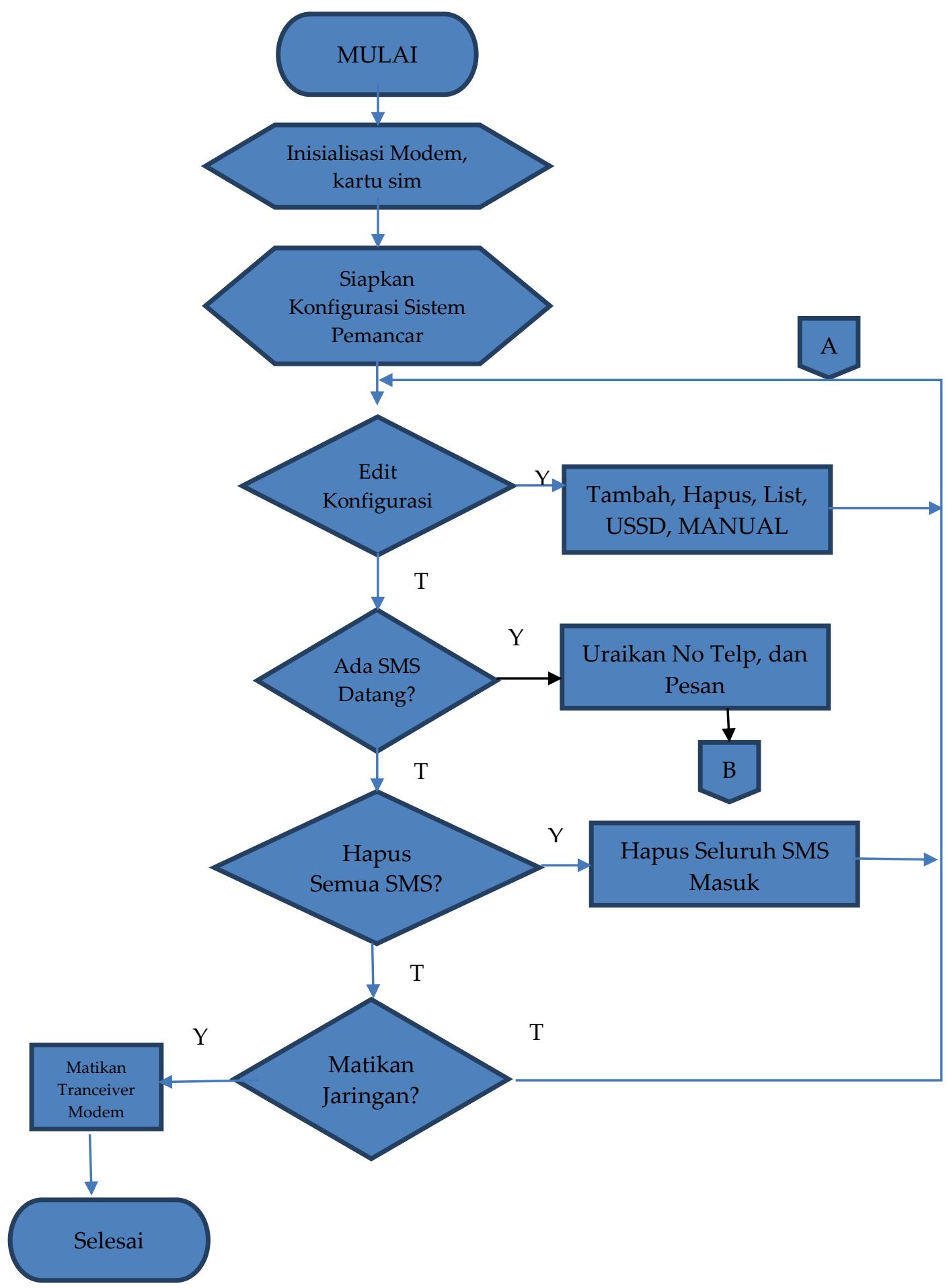

Gambar 2.a.Gaftar alir menu dan akses ke perangkat 


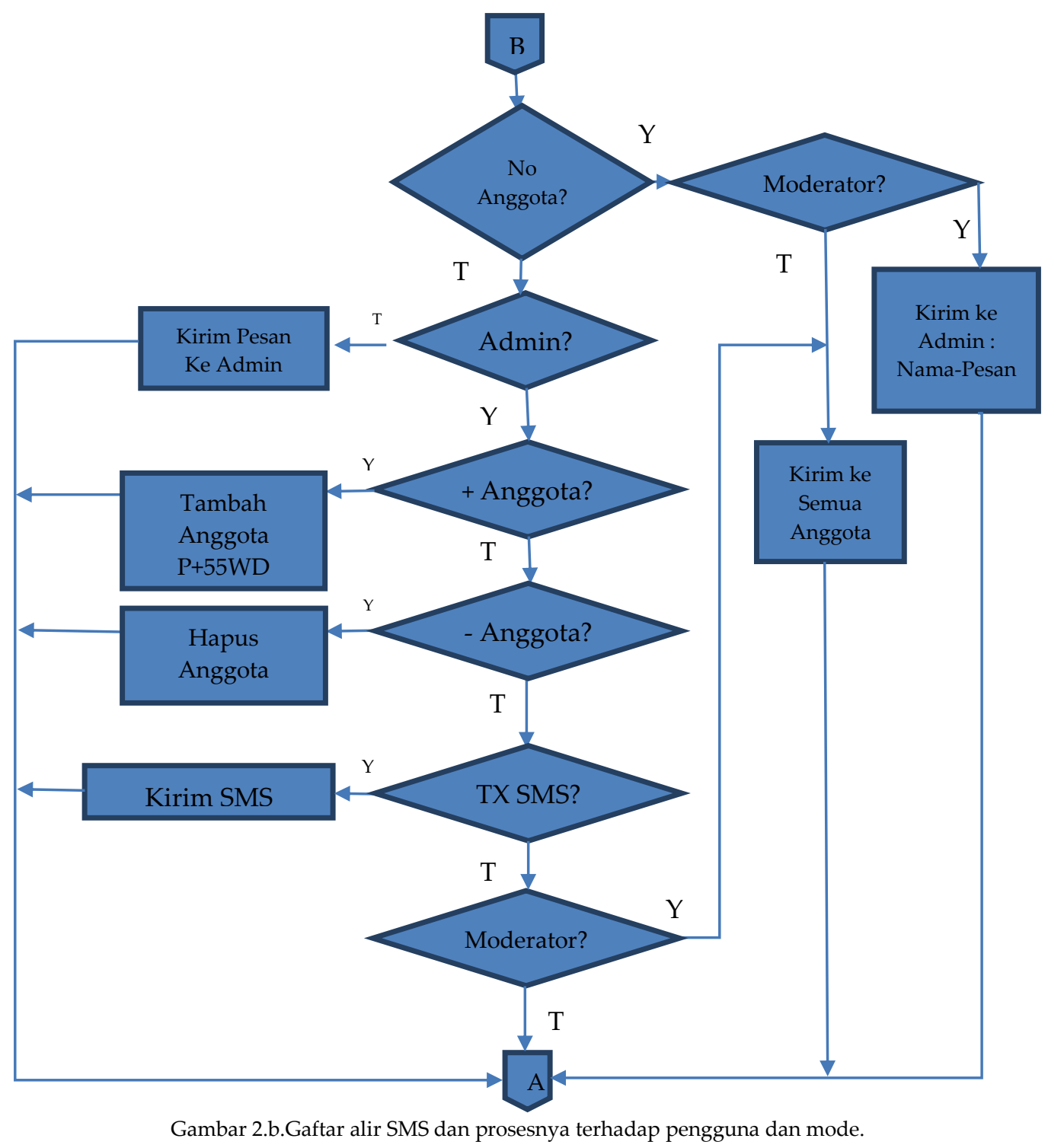

\section{Realisasi dan Hasil Percobaan}

Pada bagian ini akan ditunjukkan realisasi perangkat keras dan beberapa contoh keluaran dari skenario pengujian.

\subsection{Realisasi Perangkat Keras}

Gambar 3 menampilkan perangkat yang sudah dimasukkan ke dalam wadah. Pada papan utama terdapat bagian penting seperti mikrokontroler Atmega324, Max232, konektor ke LCD 16x2, konektor ke keyboard PS2, dan regulator tegangan. Komponen ini sesuai dengan skema yang telah diperlihatkan pada Gambar 1. 


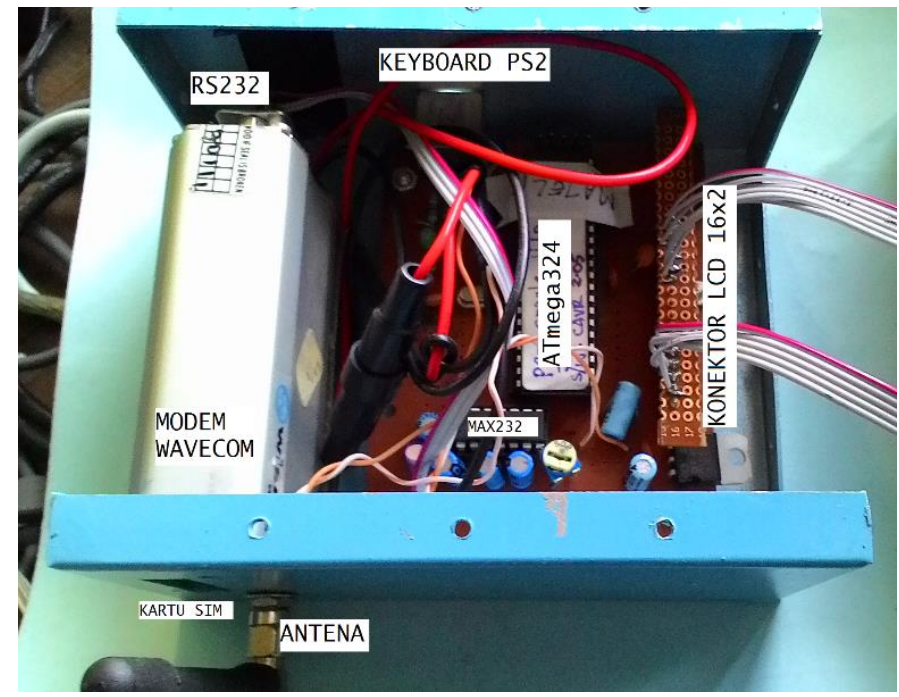

Gambar 3. Perangkat keras

\subsection{Pengujian Perangkat Keras dan Lunak}

Untuk menjelaskan hasil pengujian perangkat lunak dan keras, akan disajikan dalam beberapa skenario. Skenario pertama bertujuan untuk memperlihatkan apakah sistem berhasil menginisialisasi modem, mengambil konfigurasi awal, dan sampai ke menu utama? Skenario ke dua bertujuan untuk menguji apakah perangkat berhasil melihat, mencari, dan menghapus anggota menggunakan menu edit. Skenario ke tiga, yaitu apakah sistem dapat memancarkan pesan ke grup dengan mode moderator dan tanpa moderator, dan menambah dan menghapus anggota melalui perintah yang dikirimkan administrator melalui SMS. Skenario ke empat adalah menguji apakah pesan USSD berhasil dikirim ke operator, menerima balik balasan dari operator serta apakah modem berhasil diputus koneksinya dengan jaringan operator?

Tabel 3 menampilkan beberapa potong gambar dari empat skenario yang dicoba. Dari semua fungsi yang dicoba menunjukkan bahwa sistem telah bekerja seperti pada perancangan. Sistem ini telah dicoba implementasinya pada RT 04/01 Desa Banaran Sukoharjo untuk menyebarkan undangan pertemuan warga.

Tabel 3. Hasil Percobaan dari empat skenario.

\begin{tabular}{|c|c|c|}
\hline No & Hasil Percobaan & Penjelasan \\
\hline 1.a & $\begin{array}{l}\text { 5EDAHG WEMERIKSA } \\
\text { MODEH-RDY 2Gdt. }\end{array}$ & $\begin{array}{c}\text { Inisialisasi Modem. Sistem menunggu hubungan } \\
\text { dengan jaringan GSM. }\end{array}$ \\
\hline $1 . b$ & $\begin{array}{l}\text { SETTING MODEH } \\
\text { HARAP TUHGGU. }\end{array}$ & Memberian kondisi awal modem \\
\hline 1.c & 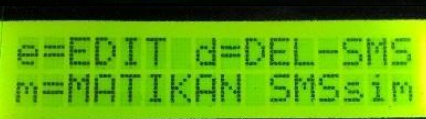 & $\begin{array}{l}\text { Sampai ke menu utama. Menekan tombol 'e' akan } \\
\text { masuk ke menu editor }\end{array}$ \\
\hline
\end{tabular}




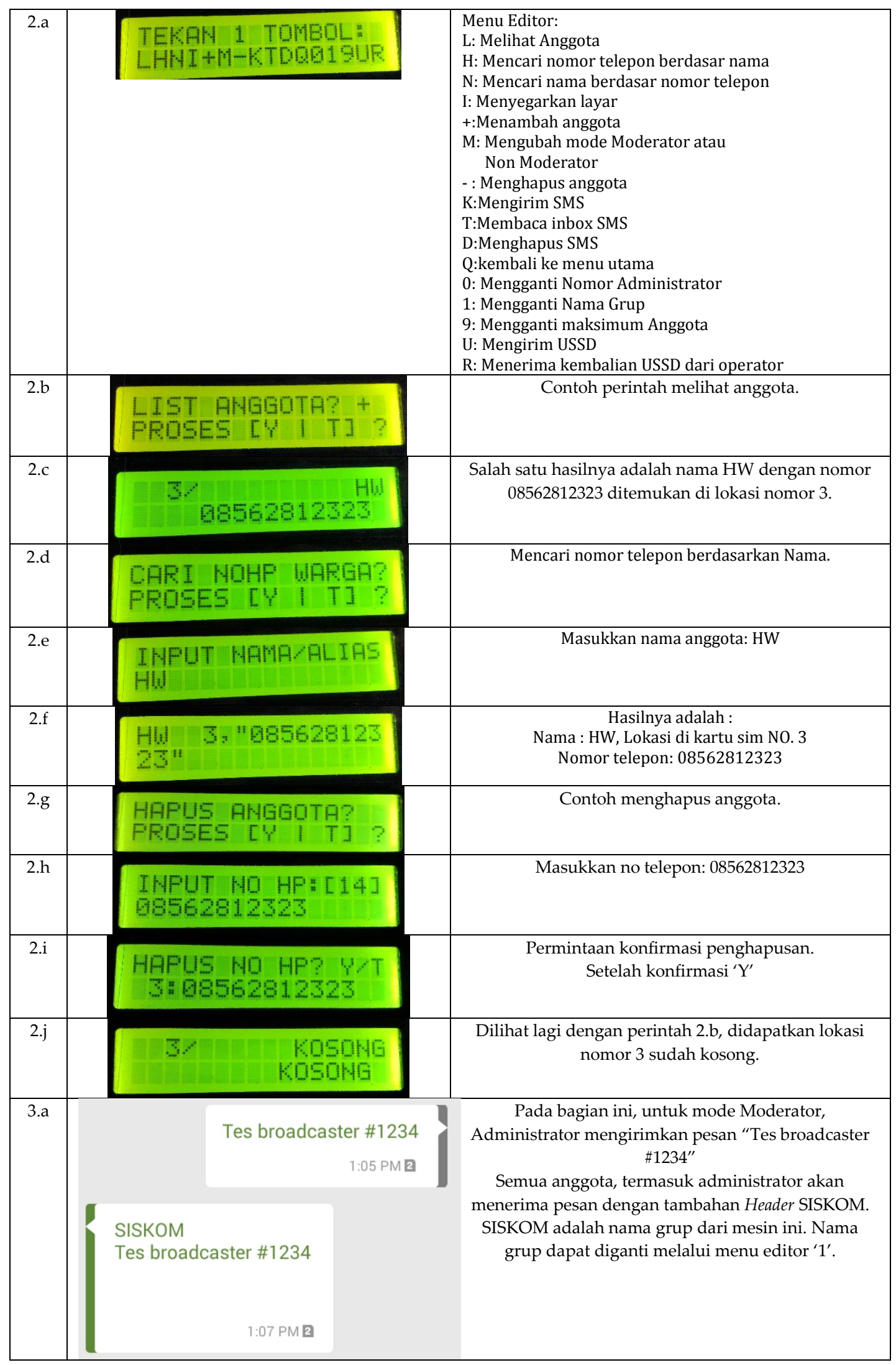




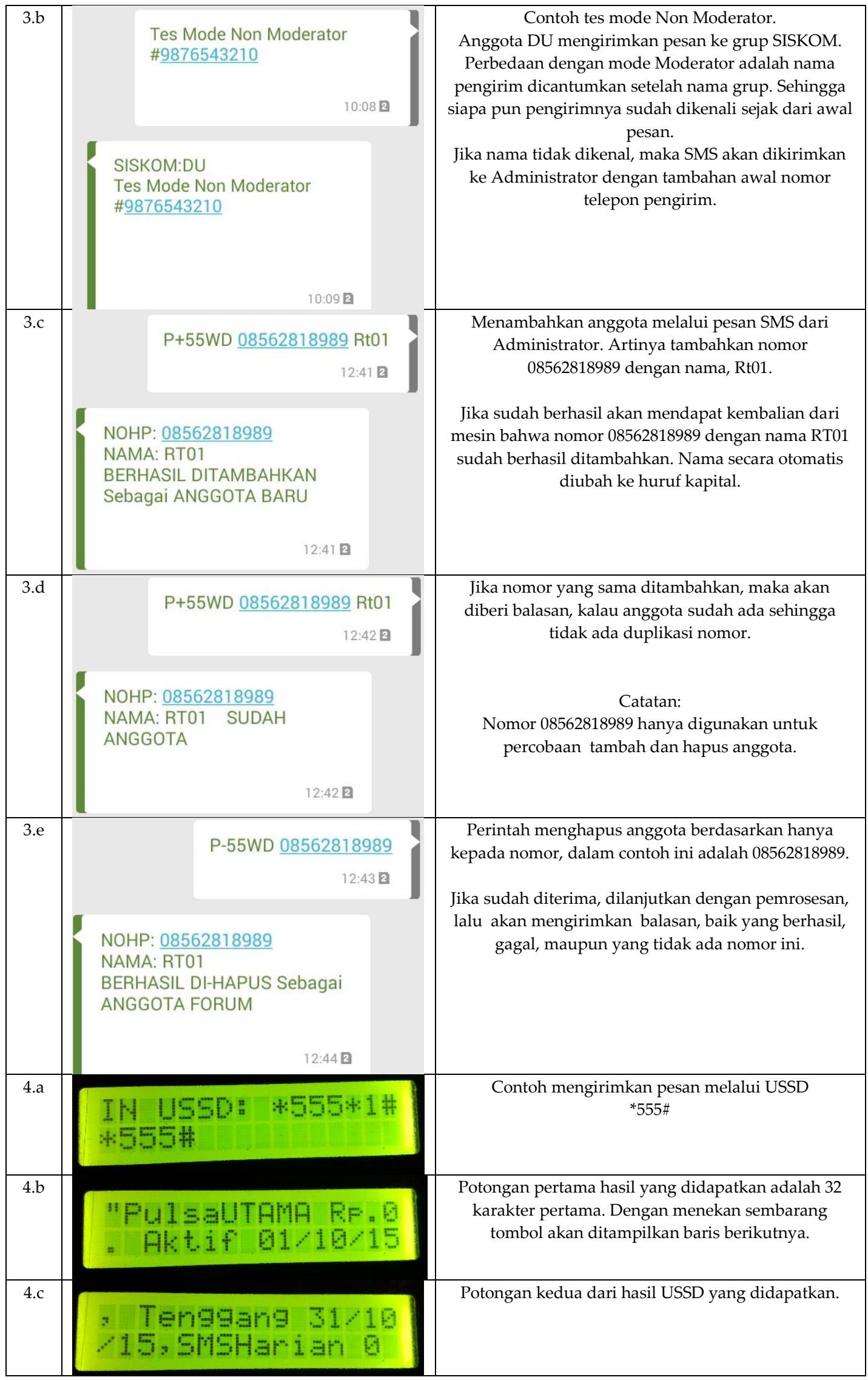


4.d

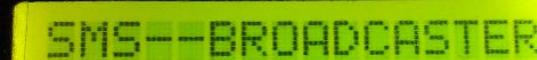
$=$ THTIS= [WHTI]
Dari menu utama, jika tombol ' $\mathrm{m}$ ' ditekan, maka modem akan diperintah untuk memutuskan hubungan dengan jaringan operator.

\section{Kesimpulan}

Sebuah mesin pengendali grup SMS mandiri telah berhasil dibuat dengan memanfaatkan modem dan sistem mikrokontroler. Pengiriman perintah melalui perangkat ataupun melalui pesan SMS. Perintah-perintah yang telah dibuat seperti menambah, menghapus, dan melihat anggota, serta pengiriman grup SMS dengan moderator dan tanpa moderator.

\section{Daftar Pustaka}

[1] ATMEL, DatasheetATmega164P/V-ATmega324P/V-ATmega644P/V, Atmel, 2015.

[2] Wavecom, AT Command Interface version 8.6, Wavecom, 2000. 
